“ (C) 2016 IEEE. Personal use of this material is permitted. Permission from IEEE must be obtained for all other uses, in any current or future media, including

reprinting/republishing this material for advertising or promotional purposes, creating new collective works, for resale or redistribution to servers or lists, or reuse of any copyrighted component of this work in other works." 


\section{The Investigation of a Segment Multi-Chamber Oscillating Water Column in Physical Scale Model}

\author{
Mohammad Shalby \& Paul Walker \\ School of Electrical, Mechanical, and Mechatronic Systems \\ University of Technology Sydney \\ Sydney, NSW 2007, Australia \\ Mohammad.Shalby@student.uts.edu.au \\ Paul.Walker@uts.edu.au
}

\author{
David G. Dorrell \\ School of Engineering \\ Howard College Campus \\ The University of KwaZulu Natal \\ Durban 4041, South Africa \\ Dorrelld@ukzn.ac.za
}

\begin{abstract}
Wave Energy Converters (WECs) are being developed as a viable green energy solution to meet power needs for coastal communities. This paper presents the initial work on a fixed multi-chamber OWC (MCOWC) concept. The paper reports theoretical and experimental modeling. It begins with initial tests to verify the simple idealized model of a fixed OWC multichamber concept. These take place under small-amplitude regular-wave wave tank conditions. The analysis is carried through to assess the effect of the Capture Width (Hydrodynamic efficiency). Experimental data is put forward from the mounting of level sensors and anemometers to test the hydrodynamic performance of a fixed MCOWC at different wave periods. The orifice effects of the chamber on the relative amplitudes of the inner free water surface and air flow rate in the duct are investigated. The experimental results will be used as real case data in order to optimize the orifice area and to maximize the chamber power according to the air flow velocity above the water surface inside the chambers.
\end{abstract}

Keywords - Renewable energy, wave energy, Oscillating water column

\section{INTRODUCTION}

Renewable energy has gained much attention and there is a substantial body of both theoretical and experimental research [1]. A wide variety of technologies have been proposed, studied and a few tested in real condition at full size [2]. Of the new technologies, wind and wave have reached a degree of mature technology. Ocean wave energy is regarded as one of the major renewable energy resources with great potential for development over the course of the next few years but it is still virtually untapped. It has the advantages of a high energy density and continual availability [2][3].

The oscillating water column (OWC) is one type of wave energy converter (WEC). It is designed to extract energy from ocean waves by using water to move trapped air and thus drive an air turbine.

The OWC device is considered as the oldest and the most widely researched type of the wave energy device. It has been successfully constructed and tested at several sites. There are several reasons for using this device; the low operational cost, and the only moving part of the energy conversion mechanism are the rotors of a turbine. Hence it has less negative environmental impact [4]. Many devices operate in real ocean waves [5]; the most powerful wave energy devices constructed were the Osprey in the UK in 1995, and the the
greenWave device in Australia in 2014. Both were rated 1 MW and near-shore plants. Both were severely storm damaged. Recently the successful deployment of a OWC at Jeju Island, South Korea, worked at rated power of $500 \mathrm{~kW}$. These successful devices show that the obstacles can be overcome with further research [6]. Table 1 summarizes most of the OWC devices that have been installed in various countries with the real or expected capacity and the turbine type that was used to extract the power.

TABLE I THE MAIN LARGE SCALE FIXED STRUCTURE OWC DEVICES INSTALLED AROUND THE WORLD THOSE SHOWN IN BOLD DID NOT WORK [6].

\begin{tabular}{|c|c|c|}
\hline Location & Capacity & Technology \\
\hline $\begin{array}{l}\text { Norway, Toftestallen, } \\
\text { near Bergen (1985) }\end{array}$ & $\begin{array}{l}500 \mathrm{~kW} \\
\text { expected }\end{array}$ & $\begin{array}{l}\text { Full-size shore-fixed OWC } \\
\text { with vertical axis Wells } \\
\text { turbine }\end{array}$ \\
\hline Japan, Sakata (1990) & $60 \mathrm{~kW}$ & $\begin{array}{l}\text { Full-size shore-fixed OWC } \\
\text { integrated with breakwater } \\
\text { with Wells turbine }\end{array}$ \\
\hline $\begin{array}{l}\text { India, Trivandrum, Kerala } \\
\text { State (1990) }\end{array}$ & $125 \mathrm{~kW}$ & $\begin{array}{l}\text { Full-size shore-fixed OWC } \\
\text { with vertical axis Wells } \\
\text { turbine }\end{array}$ \\
\hline Scotland, Island (1991) & $75 \mathrm{~kW}$ & $\begin{array}{l}\text { Full-size shore-fixed OWC } \\
\text { with Wells turbine } \\
\text { (academic purpose) }\end{array}$ \\
\hline $\begin{array}{l}\text { China, Scottish coast } \\
\text { (1995) }\end{array}$ & $\begin{array}{l}\text { 1MW } \\
\text { expected }\end{array}$ & $\begin{array}{l}\text { Full size near shore } \\
\text { bottom -standing OWC }\end{array}$ \\
\hline $\begin{array}{l}\text { Portugal, Pico, Azores } \\
\text { (1999) }\end{array}$ & $400 \mathrm{~kW}$ & $\begin{array}{l}\text { Full-size shore-fixed OWC } \\
\text { with horizontal axis Wells } \\
\text { turbine }\end{array}$ \\
\hline $\begin{array}{l}\text { Scotland, UK, A rocky } \\
\text { cliff }(2000)\end{array}$ & $500 \mathrm{~kW}$ & $\begin{array}{l}\text { Full-size shore-fixed OWC } \\
\text { with horizontal axis Wells } \\
\text { turbine }\end{array}$ \\
\hline $\begin{array}{l}\text { China, Guangdong } \\
\text { Province (2001) }\end{array}$ & $100 \mathrm{~kW}$ & $\begin{array}{l}\text { Full size shore-fixed OWC } \\
\text { with Wells turbine }\end{array}$ \\
\hline $\begin{array}{l}\text { Australia, Port Adelaide } \\
(\mathbf{2 0 0 5 )}\end{array}$ & $\begin{array}{l}1 \mathrm{MW} \\
\text { expected }\end{array}$ & $\begin{array}{l}\text { Full-size bottom- standing } \\
\text { OWC with horizontal axis } \\
\text { Wells turbine }\end{array}$ \\
\hline South Korea, Yongsoo & $500 \mathrm{~kW}$ & $\begin{array}{l}\text { Full-size bottom- standing } \\
\text { OWC with Wells turbine }\end{array}$ \\
\hline
\end{tabular}

The basic principle of the OWC is that it is a structure with one or more chambers that are open to the sea at their base. The water oscillates within the chamber and this is derived from the wave action outside the chamber(s). The motion of the air above the water surface and the air flow both in and out of the chamber drives the turbine to produce electricity [7]. 
The OWC is suitable for fixed mounted or floating configurations. Flexibility in the choice of the deployment depth and location one of the advantages of the floating device but fixed systems are still preferred on account of their simplicity and they are the focus of the present article [8].

The structure of the OWC is one of the critical design issues, one of the innovative ideas to overcome this problem is to integrate the device into a breakwater for a coastal area or harbour [9]. There are several advantages to this, such as shared construction costs, and the access for construction, operation and maintenance become much easier; this simple integration led the OWC to be successfully adopted for the first time in Sakata, Japan, in 1990.

The primary difficulties facing wave energy converters development, according to Clément [10], are: 1) the wave amplitude, phase, and direction are irregular; 2) the structural loading in the event of extreme weather conditions; 3 ) the coupling of the irregular, slow motion (frequency $<0.1 \mathrm{~Hz}$ ) of a wave to the electrical generator requires $\sim 500$ times frequency increase (to, say, $50 \mathrm{~Hz}$ ). A segmented $\mathrm{OWC}$ is one method to improve the efficiency of OWC devices with low or poor quality wavefronts at the column and is more effective in coping with random waves [3]. Using the MCOWC can significantly improve the performance of an OWC over a wide range of the frequencies compared with the single chamber case [4].

A new design of MCOWC device is put forward where the wave front travel across the front of the column rather that oncoming into the column front face. The model consists of a set of rectangular chambers with open bottoms which share single or multiple unidirectional air turbines. The proposed model has experienced various stages of development and research. Dorrell [6] describes the construction of a small multi-chambered OWC system. Then Hsieh et al [7] developed and analysed a two chamber OWC; they validated the increase in power output due to the use of the multiple chamber arrangement experimentally based on the wave conditions around Taiwan. Another model which operates using the same principle is the Sea-Breath. This is a light attenuator; it is still under development at Padova University, Italy [8]. LEANCON is a multi-chamber device that is arranged in two rows in a $\mathrm{V}$-shaped formation. The hydraulic model was evaluated at Aalborg University in Denmark [9]. Another V-shaped MCOWC, with 32 chambers, was simulated and tested at University College Cork, Ireland [10][11]. The evaluation results of the previous MCOWC models found that multiple chambers have a significant influence on the capture power efficiency in comparison to a single chamber.

There are two powerful research techniques which can be employed in the design and development of wave energy converters; these are experimental wave tank testing; and numerical modeling techniques [11].

Experimental testing of wave energy devices is a research approach that tries to recreate real conditions in a wave tank or other environment to obtain data, at lower cost than in ocean deployment, to provide significant input into the next generation of designs [12]. It has been used to develop a fundamental understanding of the hydrodynamic behaviour, to develop energy production estimates, and to obtain the loading characteristics of several wave energy converters under a broad spectrum of conditions [13][14].

In the first part of this paper the authors address physical model testing under various wave conditions and geometrical parameters when tested in the wave tank. This is done because of a lack of sufficient experimental studies on the present model. During the development stage, a regular wave was used to validate and calibrate a mathematical model [12].

In the second part of this work, the investigation of the small segment MCOWC is studied in order to assess the capture width $(C P)$. This is considered as the most common parameter used to define the performance of a WEC [15]. The $C P$ is defined as the ratio of the mean power absorption and the mean incident power.

\section{EXPERIMENTAL SETUP}

In order to calculate the capture width of MCOWC model, linear wave theory is used in conjunction with the available wave tank conditions. The amplitude of the incoming wave and the air flow through the top outlet of the chamber with an open orifice $\left(A_{2}\right)$ and without turbine are experimentally measured, then the change in chamber pressure calculated by the relationship between the air flow and the change of the pressure [16].

The wave tank used to test the MCOWC has a wave generation system with regular generation features by using a paddle wave maker. To reach deep-water waves conditions then $d / L_{0}=0.5 / 1.56<0.5$ according to [17], where $d$ is the water depth and $L_{0}$ is the tank wavelength. The absorbing beach was placed at the end of the wave tank to minimize reflections from the radiation and from the OWC itself. The wave maker can generate regular waves with periods from 0.1 to $10 \mathrm{~s}$, and a data acquisition system can control it. The test section of the wave tank is $4.3 \mathrm{~m}$ long and $0.9 \mathrm{~m}$ wide. The data in Table I summarizes the characteristics of the wave tank.

The MCOWC model was installed $1.4 \mathrm{~m}$ away from the wave maker as illustrated in Fig. 1. It was sufficiently large to be tested in the wave tank available and to avoid a scaling effect. It consists of four chambers, dividing the wavelength to four parts to allow each chamber to run as OWC. The wave drives a water surface to rise and fall in each chamber, and this oscillation generates an air flow to drive the turbines.

The experimental setup is shown in Fig. 1 shows three water level gauges $(\mathrm{G} 1, \mathrm{G} 2, \mathrm{G} 3)$ with resolution $\pm 0.15 \mathrm{~mm}$ which were situated inside the chamber to measure the instantaneous surface elevation. Four pressure sensors (P1, P2, $\mathrm{P} 3, \mathrm{P} 4)$ were used to measure the air pressure inside each chamber, which was placed at $10 \mathrm{~mm}$ distance from the upper edge of the rectangular section of the chambers.

\section{WAVE-POWER ABSORPTION BY AN MCOWC}

The first series of tests were aimed at determining the capture width which is directly related to the wave surface elevation inside the chambers. For this purpose, three level 


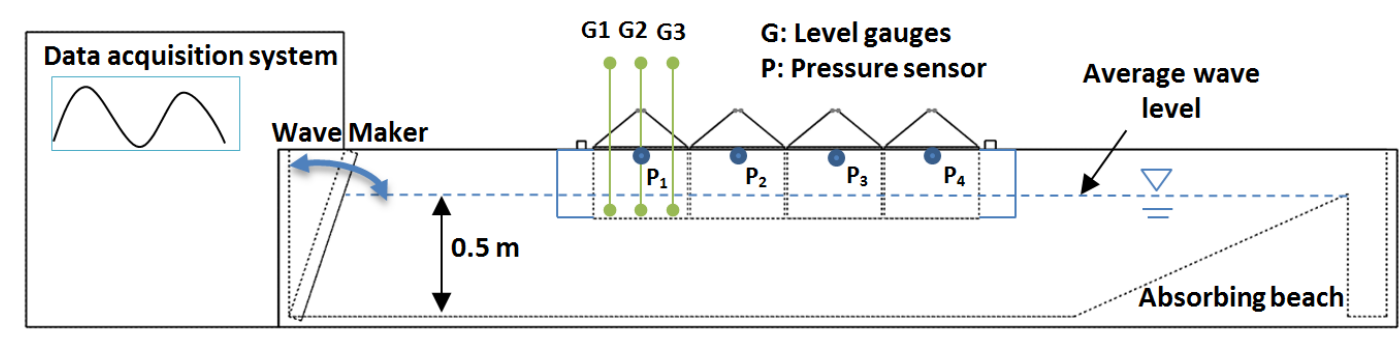

Fig. 1. Schematic of experimental setup

gauges with resolution $\pm 0.15 \mathrm{~mm}$ were situated inside the chamber to measure the instantaneous surface elevation as shown in Fig. 3. The water depth in the water tank was kept constant at $0.5 \mathrm{~m}$ for the series of experiments carried out to investigate the performance of the multi-chamber OWC under different wave conditions.

TABLE II CHARACTERISTICS OF THE WAVE TANK

\begin{tabular}{|l|l|l|l|}
\hline $\begin{array}{c}\text { Wave period } \\
{[\mathbf{s}]}\end{array}$ & $\begin{array}{c}\text { Wavelength } \\
{[\mathbf{m}]}\end{array}$ & $\begin{array}{c}\text { Average wave } \\
\text { height }[\mathbf{m}]\end{array}$ & $\begin{array}{c}\text { Average wave } \\
\text { power [W] }\end{array}$ \\
\hline 5 & 10.92 & $\sim 0$ & $\sim 0$ \\
\hline 1.6 & 3.245 & 0.044 & 0.72 \\
\hline 1.25 & 2.174 & 0.086 & 2.36 \\
\hline 1.12 & 1.79 & 0.087 & 2.22 \\
\hline 1 & 1.47 & 0.088 & 2.1 \\
\hline
\end{tabular}

The available wavelength range is longer than the chamber length, see the Table I, so that the wave surface level at one point can represent the whole surface level variation in each chamber according to [18]. In the present analysis, the water surface level at the mid-point in each chamber is used in the calculation of the chamber performance.

The hydrodynamic interaction between the OWC and the ocean waves is a complex high-order nonlinear process [15][19], under a small-amplitude wave tank conditions, it can be simplified.

The water surface profile $\eta(x, t)$ in the chambers is not flat, like a piston, as shown in Fig. 7, which influences the natural frequencies of all chambers. The mean wave height across the side face of the column [20][21] can be described by

$$
\eta(t)=\frac{H}{2} \sin (\omega t) \times \frac{\sin (\theta / 2)}{\theta}
$$

where $\omega=2 \pi / T$ is the angular frequency of the incident wave and the angular chamber length $\theta$ (rad) is defined by $\theta=2 \pi L_{c} / L\left(L_{c}\right.$ is the single chamber length, and $L$ is the wavelength). The water surface elevation inside the chambers for the current model can be modified to

$$
\eta_{n}(t) \approx \frac{H_{n}}{2} \cos \left(\omega t-\frac{(5 n-1) \theta}{5}\right) \times \frac{\sin (\theta / 2)}{\theta}
$$

where the chamber number $n=1,2,3,4$. The theoretical and experimental wave surface profiles are illustrated in Fig. 3.

The power absorbed by MCOWC corresponds to the power consume by the power take-off PTO system. In the present work, the assumption of using an open chamber with the orifice and without a turbine and the PTO was implemented through a circular orifice situated on the top of each chamber see Fig. 2 (a) and (c).

According to linear wave theory, the average power $P_{w}$ in the wave in the direction of wave propagation per crest unit width (chamber width), can be expressed as [22]

$$
P_{w}=\frac{\rho_{s} g H^{2} L b}{8 T}
$$

where $\rho_{s}$ is the water density $\left[\mathrm{kg} / \mathrm{m}^{3}\right]$, and $d$ is wave tank width in $\mathrm{m}$.

The total power available in the wave in (3) can be applied for deep to shallow water under wave theory constraints, which are satisfied in the wave tank used in this work. The energy dissipated or transferred by the waves to the sides or bottom of the tank is neglected since the length $(4.3 \mathrm{~m})$ of the tank is short. If the wave height, period and the water depth are known, the wave is fully defined and all of its characteristics can be calculated according to small amplitude wave theory, see Table II [23].

The power absorbed can be calculated using the power due to input air velocity $P_{a}$ and power due to inlet pressure $P_{p}$. The pressures and airflow velocities in this application are relatively low. The absorbed power can be obtained from

$$
P_{T}=P_{a}+P_{P}
$$

In the case of the MCOWC, each chamber works as an individual $\mathrm{OWC}$ so that the total power will be the summation of all the chambers where

$$
P_{T}=\left(P_{a}+P_{P}\right)_{1}+\ldots+\left(P_{a}+P_{P}\right)_{4}
$$

The total delivered power $P_{a}$ during one period of the incident wave can be calculated by using the integral of onequarter of the period of the incident wave to avoid the negative sign due to the water surface being lower than the mean water surface line:

$$
P_{a}=4 \int_{0}^{T / 4} \dot{P}_{a} d t
$$

The air power during one cycle can be represented by

$$
P_{a}=\frac{4 \omega^{2} \rho_{a}}{3 A_{2}^{2} k^{3}} b^{3} H^{3} \sin ^{3}\left(\frac{\theta}{2}\right)
$$

where $k=2 \pi / L$ is the wave number, $\rho_{a}$ is the air density in $\left(\mathrm{kg} / \mathrm{m}^{3}\right)$ and $A_{2}$ is the area of turbine duct (orifice), see Fig. 3 . 
The power due to the air flow $\left(P_{a}\right)$ can be simplified where $V_{2}$ is measured by an anemometer with a real time data logger which accurately reads the data - even at low velocities as shown in Fig. 5. The probe was inserted just at the opening of the inlet of the turbine duct and

$$
P_{a}=\frac{\rho A_{2} V_{2}^{3}}{2}
$$

The velocity of the air above the internal free surface of the column $V_{1}$ (Fig. 3) is

$$
V_{1}=\frac{d \eta}{d t}=\frac{\omega H}{2} \cos (\omega t)
$$

where $H$ is the internal water height peak (see Fig. 6).

According to linear wave theory, the flow is assumed incompressible, so that the axial velocity in the turbine passage is

$$
V_{2}=\frac{A_{1}}{A_{2}} V_{1}
$$

The second term of the absorbed power due to change air pressure $\left(P_{P}\right)$, which can be represented as [20]:

$$
P_{p}=\left\{\begin{array}{l}
-\frac{A_{1}}{A_{2}} \times\left(\frac{H \omega}{4}\right)^{2}\left(2 \cos (\omega t)^{2}-1\right) \\
-V_{2}\left(V_{2}-V_{1}\right) \times A_{2} \times V_{2} \times \rho_{a}
\end{array}\right\}
$$

by using (3) and (4) the capture width of an MCOWC is determined as

$$
\varepsilon_{f f}=\frac{P_{d}}{P_{w}}
$$

The calculation result of the capture width at period $T=1$ $\mathrm{s}, 1.12 \mathrm{~s}$, and $1.25 \mathrm{~s}$, are summarized in the Table III.

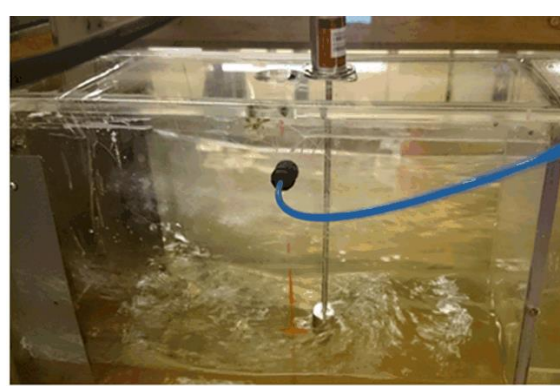

a

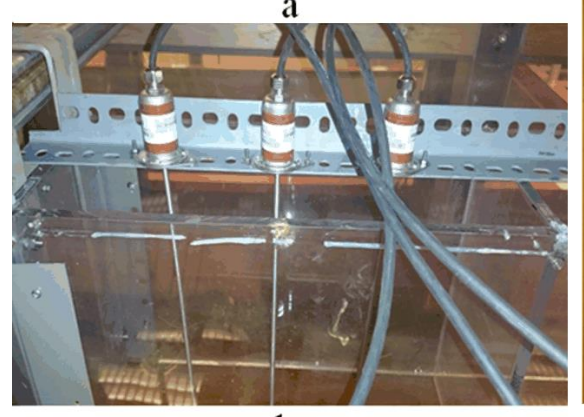

b
C

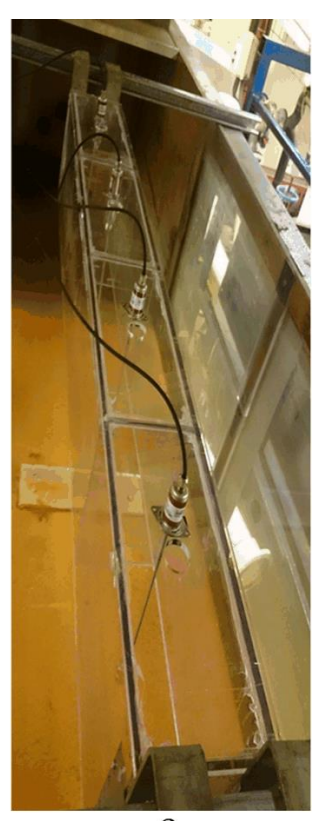

Fig. 2. MCOWC model, a) the chamber with a level sensor with the orifice; a three-level sensor with open chamber roof;c) MCOWC with level sensors and orifice.

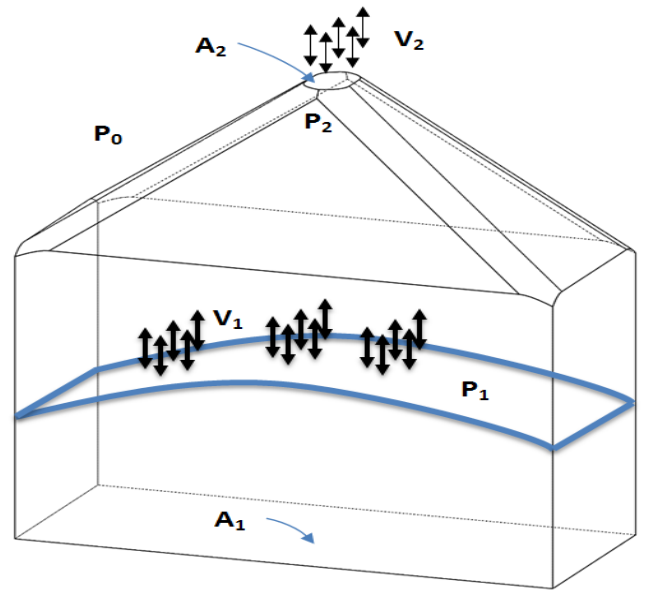

Fig. 3. Definitions of column variables.

\section{DATA ANALYSIS}

The wave height inside the chambers directly relates to the air flow velocity from (9) and an increase in air volume will enhance the velocity of the air flow at the turbine duct, which means increase the power available. Fig. 6 represents the RMS values of the wave height inside each chamber at different operating conditions (wave periods). There is a clear difference in the height of the water surface level inside each chamber which consequently leads to the production of multiple power levels during the selected period.
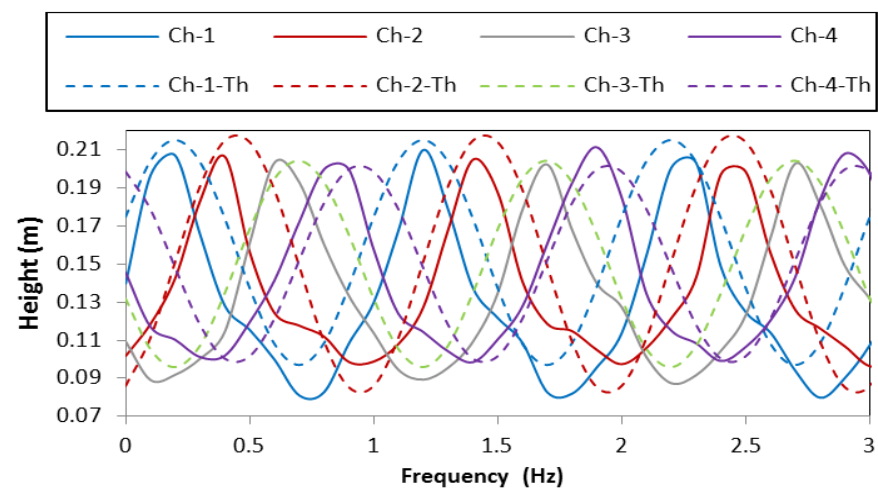

Fig. 4. The theoretical and experimental oscillation wave surface elevation inside the chambers at $1 \mathrm{~Hz}$.

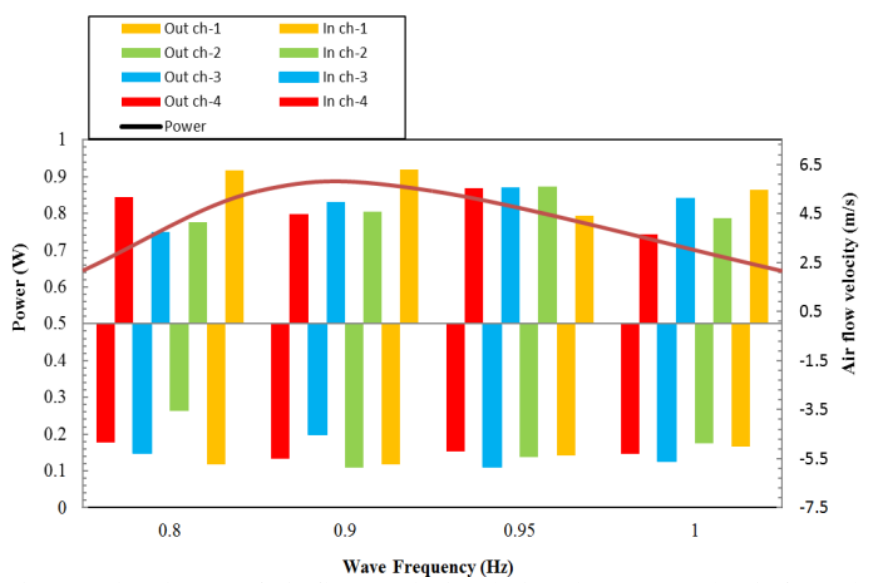

Fig. 5. The change of air flows velocity during the entry and exit from the chamber with frequency change. 


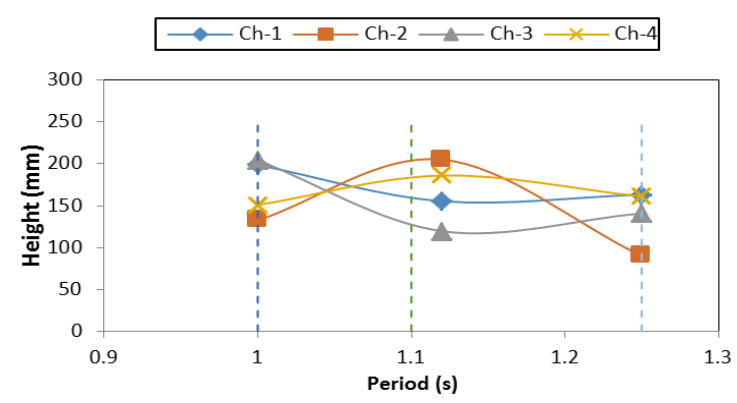

Fig. 6. RMS value of the wave height in the chambers at a different period.

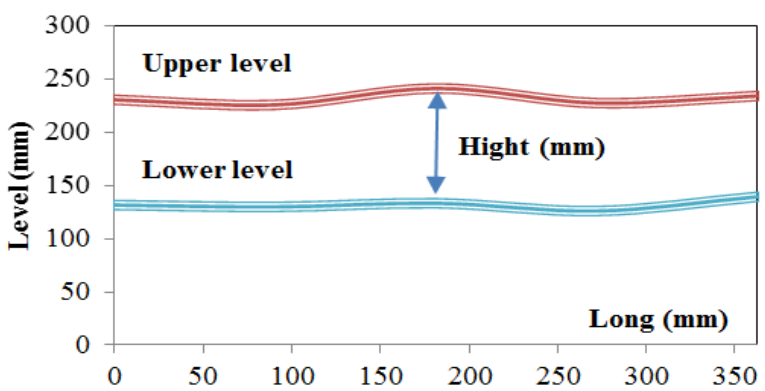

Fig. 7. The maximum and minimum free water surface profile inside chambers see Fig.2-b

TABLE III THE POWER OF THE CHAMBERs Due TO PRESSURE AND AIR FlOW AVAILABLE PERIODS

\begin{tabular}{|c|c|c|c|}
\hline \multirow{2}{*}{ Power (W) } & \multicolumn{3}{|c|}{ Period } \\
\cline { 2 - 4 } & $\mathbf{1 ~ s}$ & $\mathbf{1 . 1 2} \mathbf{~}$ & $\mathbf{1 . 2 5} \mathbf{~}$ \\
\hline$P_{a}$ & 0.232 & 0.433 & 0.304 \\
\hline$P_{p}$ & 0.43 & 0.827 & 0.6 \\
\hline$P_{T}$ & 0.662 & 1.26 & 0.894 \\
\hline
\end{tabular}

At a period 1s; the wavelength of the incident wave is nearly equal the chamber length $(1.47 \mathrm{~m})$. The relationship between the chamber length, wavelength and wave surface elevation $\eta$ is specified in (1) and (2). As can be seen in Figs. 4 and 5, the chambers work out of phase, chambers 1 and 3, work in phase, so they approximately have the same water surface level $\eta$ (see Fig. 6) which related to $V_{1}$, which in turn dictates directly to $V_{2}$ and hence the chamber power. On the other hand, chambers 2 and 4 work on the negative phase of the incident wave at the same wave period as seen in Fig. 6.

Having completed the above analysis, the power values due to the air flow were calculated for a half cycle of the water surface level oscillation inside the chambers using (6). These values can be doubled twice if the turbine is placed between the chambers so that it will be able to extract the power due to the different water oscillation phases between the chambers and much smoother in comparison with the single chamber OWC (see Fig. 6). The other term of the power is due to the pressure difference between the inlet and the outlet of the turbine. If the flow exhausted from one chamber into the next, which is out of phase, then there will be increased pressure difference so the available power will increase. These results support the idea of using the turbine between the chambers as the authors refer to previously in order to increase the capture width.

Overall, as shown in Table III, the wave period $T=1.12 \mathrm{~s}$ gives the best performance $\left(P_{T}=1.26 \mathrm{~W}\right)$ for all the three observing wave periods, due to increasing the $V_{1}$ as seen in Fig. 5. Moreover, the significant difference between the lower level and the upper level of the internal surface wave height at $T=1.12 \mathrm{~s}$ is illustrated in the Fig. 6 .

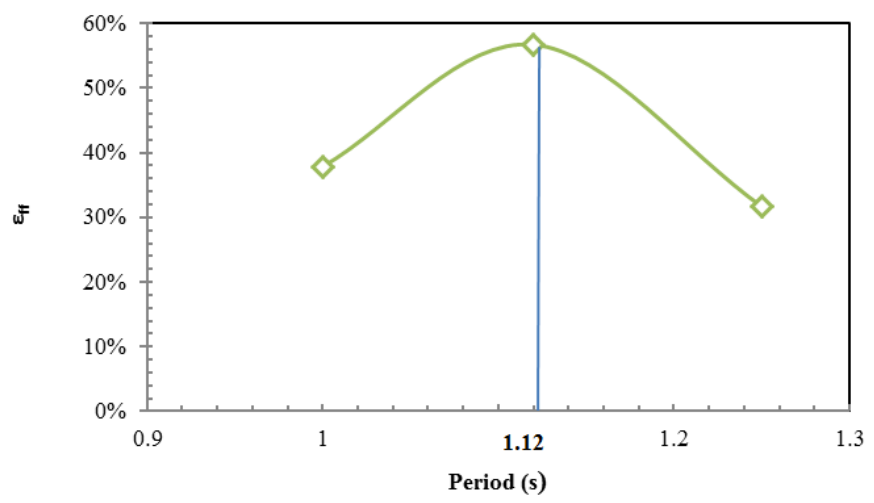

Fig. 8. The Capture width $\varepsilon_{\mathrm{ff}}$ at selected periods

The second series of tests were aimed at studying the effect of the change orifice area, which directly effects the power due to air flow velocity according to (11). The area of the orifice is a significant factor that effects $V_{2}$ and the capture width of the present model. CFD-CFX models were developed with different orifice areas of $1.48 \times 10^{-3}, 1.03 \times 10^{-3}$, and $7.38 \times 10^{-4} \mathrm{~m}^{2}$ with a period $T=1.12 \mathrm{~s}$, and height $H=$ $0.087 \mathrm{~m}$, for direct comparison. The air flow velocity immediately above the internal water surface $\left(V_{1}\right)$ was selected according to the experimental data for the proposed model $\left(A_{2}=1.03 \times 10^{-3} \mathrm{~m}^{2}\right)$, and it changed according to the change in area ratio $(0.2,0.14$, and 0.1$)$ respectively.

Obviously, the selected area orifice area $\left(A_{2}=1.03 \times 10^{-3} \mathrm{~m}^{2}\right)$ has an average peak power for the available wave tank conditions. From the continuity equation, the area ratio $\left(A_{1} / A_{2}\right)$ is the main factor governing the air flow speed which means that the same chamber can generate different air flow speed under the same wave conditions by a change in area ratio. In the case of a large orifice area, the output power will be large with higher friction loss; conversely, a small orifice area will produce less energy and less friction loss. However, the orifice area will determine the turbine duct area which in turn determines the turbine size. The experimental and simulated results of the total average available power are plotted against orifice area with constant water surface area in chamber $A_{1}$ in Fig. 9. As can be seen, for the selected area ratios, there is a significant change in the available power which means that the same chamber can generate different air flows under the same wave conditions by changing the orifice area.

The amount of energy extracted is very dependent on the wave energy that impacts onto the MCOWC in the direction of the wave propagation. The small model was built to operate in the wave tank state, but in a real state, the MCOWC should be able to change its operation according to many real sea 
states. Therefore, numerical modeling will be carried out in the next stages and this will be concerned with harmonic wave motion at a given angular frequency $\omega$ and to look at the performance that may be expected with modified configurations.

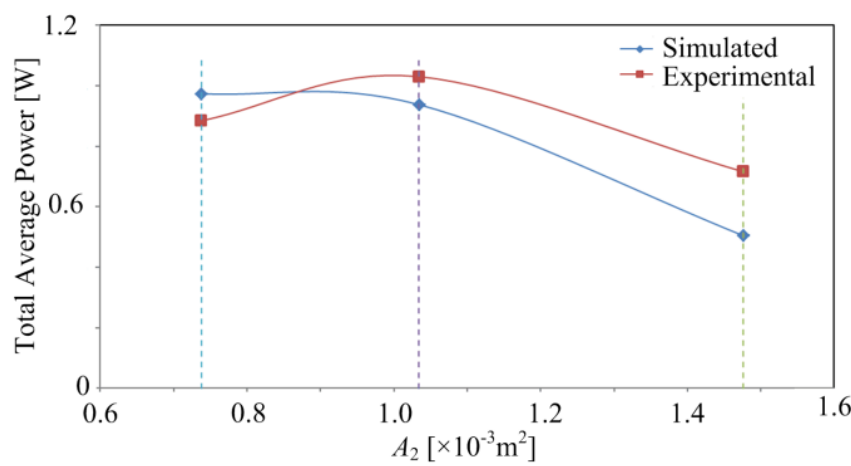

Fig. 9. Available powers in chambers versus orifice area $A_{2}$ with constant $A$ using CFD-CFX model simulation.

\section{CONCLUSIONS}

In this paper, experimental tests were carried out on a fixed MCOWC. This has a top orifice of area $A_{2}$ and was open at the bottom with area $A_{1}$. The tests allowed the performance of the MCOWC to be investigated in a wave tank.

The behaviour of the oscillating water surface inside the chambers, and the air flow through the turbine duct $A_{2}$, were studied. Regular waves were used. The model size was small, and the wave tank conditions were far from the energy available in ocean waves, so that the air flow efficiency was low. As a consequence, the measured efficiency was low. However, this will increase with up-scaling.

The developed model is validated by the experimental results obtained in the wave tank. The simulations allowed for changing conditions which would occur in a real ocean. From the model prediction work, a suitable design will be proposed. This MCOWC design will be based on numerical modeling. CFD models that approximate the Navier-Stokes equations are also proposed for the next part of the project.

\section{ACKNOWLEDGMENT}

The authors would like to sincerely thank Al-Hussein Bin Talal University for their financial support given through doctoral scholarship to the student Mohammad Shalby.

\section{REFERENCES}

[1] Y. Hua, M. Oliphant, and E. J. Hu, "Development of renewable energy in Australia and China: A comparison of policies and status," Renewable Energy, vol. 85, pp. 1044-1051, 2016.

[2] J. Falnes and J. Løvseth, "Ocean wave energy," Energy Policy, vol. 19, pp. 768-775, 1991.

[3] J. Cruz, Ocean wave energy: current status and future prespectives Springer Science \& Business Media, 2007.

[4] T. Heath, "A review of oscillating water columns," Philosophical Transactions of the Royal Society of London A: Mathematical, Physical and Engineering Sciences, vol. 370, pp. 235-245, 2012.

[5] T. Heath, T. Whittaker, and C. Boake, "The design, construction and operation of the LIMPET wave energy converter (Islay, Scotland)," in 4th European wave energy conference, 2000, pp. 4-6.
[6] A. F. Falcão and J. C. Henriques, "Oscillating-water-column wave energy converters and air turbines: A review," Renewable Energy, Vol. 85, Jan, 2016, pp 1391-1424.

[7] D. Evans and R. Porter, "Hydrodynamic characteristics of an oscillating water column device," Applied Ocean Res., vol. 17, pp. 155-164, 1995.

[8] Z. Chen, H. Yu, M. Hu, G. Meng, and C. Wen, "A review of offshore wave energy extraction system," Advances in Mechanical Engineering, vol. 5, p. 623020, 2013.

[9] A. F. Falcão, Modelling of Wave Energy Conversion, Instituto Superior Técnico, Universidade Técnica de Lisboa, 2014

[10] A. Clément, P. McCullen, A. Falcão, A. Fiorentino, et al., "Wave energy in Europe: current status and perspectives," Renewable and Sustainable Energy reviews, vol. 6, pp. 405-431, 2002.

[11] Y. Luo, J.-R. Nader, P. Cooper, and S.-P. Zhu, "Nonlinear 2D analysis of the efficiency of fixed oscillating water column wave energy converters," Renewable Energy, vol. 64, pp. 255-265, 2014.

[12] V. Heller, "Development of Wave Devices from Initial Conception to Commercial Demonstration," Reference Module in Earth Systems and Environmental Sciences, Ocean Energy, vol 8, 2012 Pages 79-110.

[13] P. Schmitt, K. Doherty, D. Clabby, T. Whittaker, "The Opportunities and Limitations of using CFD in the Development of Wave Energy Converters," RINA Marine and Offshore Energy Conf., 2012.

[14] J. P. Kofoed and P. Frigaard, "Development of wave energy devices: The Danish case/the dragon of nissum bredning," Renewable Ocean Energy, Vol. 4, No. 4, 2009, pp 83-96

[15] M. Folley, Numerical Modelling of Wave Energy Converters: State-of the-Art Techniques for Single Devices and Arrays, Elsevier, 2016.

[16] O. Malmo and A. Reitan, "Wave-power absorption by an oscillating water column in a channel," Journal of Fluid Mechanics, vol. 158, pp. $153-175,1985$

[17] P. Boccotti, Wave Mechanics for Ocean Engineering, Elsevier, 2000.

[18] A. Brendmo, J. Falnes, and P. Lillebekken, "Lineår modelling of oscillating water columns including viscous loss," Applied Ocean Research, vol. 18, pp. 65-75, 1996.

[19] J. Falnes, Ocean waves and oscillating systems: linear interactions including wave-energy extraction, Cambridge university press, 2002.

[20] D. G. Dorrell, M.-F. Hsieh, and C.-C. Lin, "A small segmented oscillating water column using a Savonius rotor turbine," IEEE Transactions on Industry Applications, vol. 46, pp. 2080-2088, 2010.

[21] D. G. Dorrell and M.-F. Hsieh, "Performance of Wells turbines for use in small-scale oscillating water columns," in The Eighteenth International Offshore and Polar Engineering Conference, 2008.

[22] L. H. Holthuijsen, Waves in oceanic and coastal waters, Cambridge University Press, 2010

[23] R. M. Sorensen, "Two-dimensional wave equations and wave characteristics," Basic Coastal Engineering, Chapter 2, pp. 9-52, 2006 